\title{
Una nueva geografía latinoamericana en el tránsito de la planificación a la gobernanza, del desarrollo al crecimiento
}

\author{
Carlos A. de Mattos | Mayo - Junio 2010 \\ El siguiente texto reproduce la conferencia dictada por Carlos A. de Mattos, académico de Instituto de Estudios Urbanos \\ y Territoriales (IEUT) de la Pontificia Universidad Católica de Chile, al momento de recibir el Premio Internacional de \\ Geocrítica, durante el XI Coloquio Internacional de Geocrítica, realizado en la ciudad de Buenos Aires entre el 2 y 7 de \\ mayo pasado, organizado por el Instituto de Geografía y el Departamento de Geografía, de la Facultad de Filosofía y Letras \\ de la Universidad de Buenos Aires.
}

Este Premio Internacional viene siendo otorgado desde el año 2002 durante la realización de los coloquios internacionales de Geocrítica. Hasta ahora el Premio ha sido otorgado a los profesores Elías Trabulse (México) en el año 2002, Roberto Lobato Correa (Brasil) en 2003, Thomas F. Glick (Estados Unidos) en 2004, Pedro Cunill (Chile) en 2005, Robert Herin (Francia) en 2006, Jorge B. Gaspar (Portugal) en 2007, José Manuel Naredo (España) en 2008, Camilo Domínguez (Colombia) en 2009 y Carlos A. de Mattos (Uruguay) en 2010. En esta oportunidad, el jurado internacional de Geocrítica otorgó el Premio al profesor de Mattos "por sus aportaciones a la construcción de una teoría crítica de la ciudad y su contribución al pensamiento urbano iberoamericano".

Esta conferencia fue dictada en el acto de clausura del XI Coloquio Internacional, el día 7 de mayo del 2010 en el Auditorio Jorge Luis Borges de la Biblioteca Nacional de la República Argentina.

Con la comunicación informándome que se me había concedido el Premio Internacional de Geocrítica 2010, también recibí la indicación de que tenía que preparar una presentación glosando mi trayectoria intelectual y profesional. En ese momento comprendí que tenía que hacerme cargo de una tarea que nunca había realizado y que hasta entonces no había estado en mis planes realizar. En todo caso, también entendí que desde que había aceptado la muy honrosa distinción que significaba el otorgamiento de este prestigioso Premio, tenía que intentar cumplir de la mejor manera que me fuese posible con esa tarea.

Para hacerlo, consideré que debía intentar plantearme y dar respuesta a algunas preguntas sobre aquellos aspectos de mis actividades y trabajos que supuse habían sido los que el jurado de Geocrítica había tenido en cuenta al tomar la decisión de otorgarme este premio. De acuerdo a como lo interpreté, tales preguntas, en lo esencial, deberían hacer referencia a aspectos como los siguientes: ¿por qué, cuándo y cómo me interesé por los temas y problemas urbano-territoriales y decidí dedicarme a su estudio?; ¿ ¿cuáles han sido las posturas que fui adoptando a medida que logré avanzar en esa tarea?; ¿cuáles han sido los ejes argumentales e ideológicos centrales que marcan mis investigaciones y trabajos?; ¿cómo han evolucionado mis posiciones al respecto a lo largo de estos años?

Para esbozar algunas respuestas a estas preguntas, y ubicar y explicar cómo y por qué me orienté hacia el estudio de estos temas, consideré que era necesario relacionar mi evolución personal con algunos de los hechos que tuvieron mayor incidencia en mi proceso de formación y socialización. Todo esto, teniendo en cuenta los cambios políticos, sociales y económicos de la historia reciente de estos países que influyeron especialmente en esa evolución; tal es el caso, en particular, de las mutaciones en la orientación de los objetivos y de las modalidades de la gestión pública que se produjeron a mediados de la década de los años setenta del siglo pasado. 
Asimismo, para estructurar este relato también tuve en cuenta el hecho de que las instituciones y los grupos humanos a los que me vinculé a lo largo de mi vida profesional influyeron profundamente en la forma en que se procesó y orientó mi evolución ideológica y, sobre todo, en cómo las posiciones que fui asumiendo en esa evolución cristalizaron en algunos trabajos que, en su momento, intentaron contribuir al esclarecimiento de los temas y problemas que me preocupaban.

Para ubicar estas reflexiones, quiero comenzar haciendo una rápida digresión acerca de cómo se desarrolló mi proceso de inserción social en Montevideo, ciudad a la cual llegué para completar mis estudios secundarios desde el interior del Uruguay, y sobre cómo este proceso incidió en algunas decisiones que fueron determinantes en la elección del rumbo por el que finalmente me encaminé.

Para esto, importa destacar que en esa época Montevideo era una ciudad que, ante todo, miraba hacia Europa y mostraba escaso interés por lo que ocurría en América Latina. En ese ámbito, jugó un importante papel en mi proceso de inserción en la vida social montevideana mi temprana vinculación a algunos círculos intelectuales que por ese entonces eran conocidos en esta ciudad como "barras de café", debido a que su lugar de encuentro y deliberación se ubicaba en alguno de los numerosos grandes cafés que existían en esa época en esta ciudad; allí, en uno de esos círculos o barras de café, fue que comencé a participar en interminables discusiones que, en lo fundamental, se relacionaban con temas relativos a la literatura, el teatro, el cine y la pintura.

Fue mi relación con estos temas lo que, en definitiva, incidió con mayor fuerza en el camino que terminé por escoger para mi formación académico-profesional, pues cuando tuve que optar por un área de estudio, luego de algunas marchas y contramarchas, terminé inclinándome por la arquitectura, antes que todo por su vinculación con las cuestiones del arte.
Hecha esta opción, a poco de llegar a la Facultad de Arquitectura, me encontré enfrentado a un radical cambio de rumbo, que terminó por provocar una imprevista mutación en la orientación de mis principales preocupaciones. Esto ocurrió como consecuencia de que el mismo año en el que ingresé a esta Facultad, se produjo una suerte de sublevación estudiantil, como reacción frente a una enseñanza descontextualizada y formalista que prácticamente no guardaba relación alguna con los problemas que se planteaban en la realidad nacional de la que formaba parte. Lo que buscaba el movimiento estudiantil era un cambio de orientación y contenido del plan de estudios de arquitectura y urbanismo, de forma de reenfocarlos hacia la realidad y los problemas arquitectónicos, habitacionales y urbanos del Uruguay de esos años.

Mi participación en ese proceso reformista, en el que me involucré de inmediato, produjo un cambio substancial en mi visión sobre la arquitectura y el arquitecto, cambio que en no mucho tiempo ocasionó un desplazamiento del centro de mis preocupaciones desde la arquitectura hacia la ciudad y el territorio. Este desplazamiento redundó en que mis estudios de arquitectura terminaran produciendo más que un arquitecto: una híbrida mezcla de geógrafo, economista y sociólogo.

Y, además, ese cambio de preocupaciones me llevó, de manera natural, a encaminarme a la militancia gremial estudiantil, en un proceso que transitó desde mi participación como dirigente del centro de estudiantes de arquitectura (del que fui presidente en más de una oportunidad), hacia la Federación de Estudiantes Universitarios del Uruguay (de la que terminé siendo Secretario General). Y ello se tradujo en algunos, en realidad demasiados, años de activismo gremial estudiantil, ya no solamente en el plano nacional, sino también en el internacional, con lo cual allí se inició mi condición de viajero frecuente.

En definitiva, la reforma del plan de estudios de la Facultad de Arquitectura terminó provocando una radical alteración de mis preocu- 
paciones centrales, que se movieron desde las cuestiones relacionadas con el mundo del arte, hacia los problemas geográficos, económicos y sociales, al mismo tiempo que mi militancia en el gremialismo estudiantil intensificó mi interés por la perspectiva latinoamericana. Este cambio de perspectiva no hizo más que reafirmarse desde entonces.

De tal forma, cuando terminé mis estudios y obtuve mi título de arquitecto, ya tenía muy claro que el ejercicio individual de esta profesión había dejado de interesarme y que, en su lugar, había ido creciendo el interés por un conjunto de temas que estaban mucho más próximos a los campos disciplinarios de la geografía, la economía y la sociología. Fue entonces, desde esta perspectiva, que comencé a incursionar en los temas de la planificación del desarrollo económico, que hacia fines de la década de los sesenta se habían situado en el centro de la discusión sobre el futuro de estos países, en un ámbito donde los análisis y las propuestas de la CEPAL habían comenzado a adquirir un creciente protagonismo.

Por ese camino, luego de integrar por un tiempo un equipo que asesoraba al gobierno uruguayo en la elaboración del plan nacional de educación, obtuve una beca para realizar estudios de postgrado en el Instituto Latinoamericano de Planificación Económica y Social (ILPES) en Santiago de Chile. Fue de esta manera, como inicié mi vinculación con la CEPAL y el ILPES, instituciones a las que a partir de entonces estuve vinculado por más de veinte años. Por ese entonces, el ILPES, que había sido fundado y liderado por el economista argentino Raúl Prebisch con el propósito de dar respuesta a las demandas de asistencia técnica en el área de planificación económica y social que entonces planteaba un número creciente de gobiernos latinoamericanos, había pasado a constituirse en el principal think tank en esta materia para toda América Latina y gozaba de considerable prestigio continental.

Terminados mis estudios de postgrado en Santiago, a mi retorno al Uruguay pasé a tra- bajar en el Comité de Inversiones y Desarrollo Económico (CIDE), que entonces fungía como oficina nacional de planificación en Uruguay, por lo que poco después habría de transformarse en la Secretaría de Planeamiento y Presupuesto de la Presidencia de la República; en este ámbito, donde me desempeñé en el equipo técnico del sector planificación regional y urbana, quedó decidida en forma definitiva mi dedicación a estos temas.

Aun cuando desde la conclusión de mis estudios de postgrado en CEPAL-ILPES en Santiago había continuado colaborando con cierta frecuencia con las actividades de capacitación que allí se desarrollaban, y había recibido más de una invitación para incorporarme a su planta laboral, entonces mi intención era continuar desarrollando mis actividades en Uruguay. Sin embargo, al poco tiempo la situación política uruguaya comenzó a deteriorarse y, al mismo tiempo, el gobierno de la época despojó de la mayor parte de sus funciones a la repartición pública en la que entonces me desempeñaba, con lo cual se fue desvaneciendo mi interés por el trabajo profesional que allí realizaba. En esas circunstancias, al recibir una nueva invitación del ILPES, tomé la decisión de trasladarme a Chile por un lapso de dos años, que terminaron siendo más de cuarenta.

En ese momento el ILPES era un ambiente de trabajo sumamente estimulante, dotado de una amplia y prestigiosa planta profesional y con una importante proyección e influencia en América Latina. En ello, la presencia de Prebisch tenía singular relevancia, tanto por su fuerte liderazgo intelectual, como por su infatigable capacidad para generar nuevas ideas, propuestas y discusiones en toda la región. En esta situación, el ILPES llegó a convertirse en esa época en uno de los principales focos de discusión y de irradiación en los temas del desarrollo y la planificación. Todo ello tuvo un fuerte impacto en mi evolución y formación profesional y en mi vinculación a los temas y a la realidad de estos países. 
En esta evolución también influyó de manera significativa el área de trabajo para la que fui reclutado, pues en ella me correspondió hacerme cargo por varios años del dictado de numerosos cursos en distintos países y ciudades latinoamericanas, cursos éstos que se constituyeron en verdaderos foros de intercambio y de revisión crítica de las ideas y propuestas que en ese entonces los funcionarios del ILPES teníamos la misión de explicar y difundir. Otro hecho que tuvo mucha importancia en mi evolución personal en este período, está relacionado con el hecho de haber pasado a residir en Chile, pues en este país la cuestión latinoamericana tenía mucho más importancia e interés que en el Uruguay de fines de la década de los sesenta.

Por otra parte, durante el período en que he residido en Chile, he podido ser testigo directo de una sucesión de experimentos de distinto signo político que se propusieron, cada uno a su manera, poner en práctica una estrategia diferente para promover el desarrollo y/o el crecimiento. El haber estado inmerso en esta diversidad de experimentos, se constituyó en una oportunidad excepcional para participar en el análisis y la discusión cotidiana sobre el significado, el alcance y la viabilidad de cada uno de ellos, lo cual en ciertos casos me obligó a revisar, e incluso a rectificar, posturas teóricas o convicciones personales asumidas previamente.

Cuando llegó a su término esta etapa de más de dos décadas en las que pude desarrollar mis actividades profesionales en el ILPES, recibí una invitación para incorporarme a la planta académica del Instituto de Estudios Urbanos de la Pontificia Universidad Católica de Chile, la que hizo posible concretar un reencuentro con el medio y con la actividad universitaria con el que había venido fantaseando desde tiempo atrás. En ese momento, esto se me presentó como una imprevista oportunidad de revitalización personal y profesional, sobre todo por cuanto la institución que abandonaba ya había cumplido su ciclo y, fracaso de la planificación mediante, sobrevivía carente de rumbo y de una misión precisa.
Más allá de que con este retorno a la vida universitaria logré tener una mayor dedicación a las tareas de docencia y de investigación, ello también hizo posible mi vinculación a algunas actividades complementarias que me atraían de manera especial. En particular, este nuevo ámbito laboral me dio la posibilidad de integrarme a los trabajos de preparación y edición de la Revista EURE, de cuyo Comité Editorial pasé a formar parte de inmediato, para posteriormente, entre 2003 y 2009, hacerme cargo de su dirección. Esta actividad me permitió establecer e intensificar nuevas modalidades de comunicación y cooperación con la comunidad de investigadores urbano-regionales de lengua castellana y portuguesa, en la medida en que la revista se constituyó en un medio efectivo para la difusión de muchos de los trabajos que esa comunidad venía produciendo.

Por último, no puedo dejar mencionar a la Red Iberoamericana de Investigadores sobre Globalización y Territorio, que creamos con un grupo de amigos y colegas latinoamericanos y españoles con ocasión de un encuentro realizado en 1994 en la ciudad de Pereira, Colombia; esta Red, de cuya coordinación y animación estuve a cargo durante sus primeros años, ha logrado mantenerse activa hasta el día de hoy, cobrando una dimensión y una vitalidad que no pudimos anticipar en el momento de su creación. Su existencia y continuidad permitieron establecer un mecanismo abierto, flexible e interdisciplinario de comunicación e intercambio para una cada día más numerosa comunidad de investigadores sobre temas territoriales del mundo de habla castellana y portuguesa. En lo que me atañe en forma personal, tengo que reconocer que me he beneficiado ampliamente de la existencia de esta Red, dado que buena parte de las investigaciones que he utilizado como base para mis trabajos más recientes tienen esa procedencia.

¿Cómo evolucionaron mis preocupaciones y puntos de vista a lo largo del proceso reseñado hasta aquí? La respuesta, es que lo hicieron relacionadas estrechamente a los 
cambios que se fueron produciendo durante estos años en cuanto a la orientación y el contenido de las fórmulas dominantes para superar los principales problemas económicos y sociales de estos países. A este respecto, si tuviese que sintetizar esos cambios, diría que ellos estuvieron marcados por la transición desde las propuestas sobre la planificación del desarrollo económico y social, a las de una gobernanza subsidiaria y empresarialista, como medio para promover el crecimiento económico. En otras palabras, los objetivos pasaron desde el desarrollo al crecimiento, y los medios desde la planificación a la gobernanza, lo que habría de tener connotaciones fundamentales.

En la época del desarrollo y de la planificación del desarrollo

Fue en el período que se inició con la segunda posguerra cuando comenzó a afirmarse en todo el mundo -y en particular en los países latinoamericanos- un discurso teórico-ideológico estructurado bajo una fuerte influencia keynesiana, el cual ponía el acento en dos ideas en torno a las que se vertebraron las aspiraciones de quienes actuaron en este campo durante las tres décadas siguientes: el desarrollo económico y social y su planificación, donde, en lo esencial, el componente social incluyó algunos aspectos de las propuestas del Estado de Bienestar.

$\mathrm{Al}$ mismo tiempo, en este discurso, la industrialización fue considerada como el componente básico para lograr avanzar hacia un mayor desarrollo económico. Si bien la industrialización ya había sido desde tiempo atrás un objetivo importante de las políticas públicas en algunos de estos países, fue en los años posteriores a la Segunda Guerra Mundial cuando la propuesta respectiva adquirió su mayor ascendiente intelectual y político, en especial desde el momento en que la misma se ubicó como el eje del modelo normativo preconizado por la CEPAL.

De hecho, a medida que este enfoque comenzó a ganar ascendiente político, fue posible comprobar que los objetivos que realmente llegaron a tener prioridad efectiva donde las políticas respectivas llegaron a aplicarse, fueron los relativos a la industrialización y a la integración económico-geográfica capitalista; en contraposición, otros objetivos, como los sociales y territoriales, no llegaron a tener mucho más que un carácter discursivo.

Fue así que con los avances de la industrialización y de la integración geográfica, la construcción social emergente fue adquiriendo o fortaleciendo un conjunto de propiedades que, a la larga, se constituyeron en obstáculos insalvables para poder materializar los ejercicios de ingeniería social que suponía la planificación desarrollista normativa y centralizada. Ante esta situación, importa considerar que en los análisis y en las discusiones de esa época se fue acentuando la divergencia entre dos posturas básicas con respecto a la viabilidad y al posible alcance de una intervención planificada de esos procesos, la cual tenía su origen en la importancia que cada una de ellas atribuía al hecho de que las formaciones emergentes estuviesen regidas por relaciones capitalistas de producción y por las propiedades y limitaciones que les eran inherentes.

¿Cómo me ubiqué en relación a esta divergencia? A partir del análisis de los antecedentes y la información que fui recogiendo en los distintos países en los que por entonces desarrollaba mis actividades $-\mathrm{y}$, en especial, de los elementos de juicio que me aportaron las numerosas discusiones en las que pude participar en esos países- me reafirmé en la convicción de que para entender la evolución y los cambios en esta región era ineludible hacerlo a la luz de las constricciones que se derivaban de las propiedades y de las reglas del juego que se habían impuesto a medida que la mayoría de esos países avanzaba en su formación como sociedades capitalistas. Lo cual, en lo esencial, significa aceptar que los cambios factibles en una sociedad de esta naturaleza están acotados por una propiedad básica y medular que le 
es constitutiva e insoslayable, que fue sintetizada por Habermas (1975, p. 50) en la forma siguiente:

[...] no podrá hablarse de planificación de los recursos escasos mientras las prioridades de la sociedad global se establezcan de manera espontánea, es decir, como efecto secundario de las estrategias adoptadas por las empresas privadas.

El alcance de esta afirmación, que a mi juicio sintetiza un rasgo medular del tipo de construcción social que se ha venido afianzando a lo largo del continuo y persistente proceso de modernización capitalista vivido por estos países, me reafirmó en la convicción de que con ello se había impuesto una situación de creciente dependencia estructural de estas sociedades con respecto al capital, lo cual, en lo medular, implica que en una sociedad regida por relaciones sociales capitalistas tienden a fortalecerse tres aspectos fundamentales:

- en primer lugar, que la posibilidad de alcanzar mayores niveles de inversión y, consecuentemente, de aumentar la tasa de crecimiento económico, se encuentra cada vez más estrictamente condicionada por la ganancia que esperan obtener los propietarios y/o administradores del capital en el lugar en el que materializan sus inversiones;

- en segundo lugar, que con la formación y expansión de un espacio capitalista de acumulación de cobertura planetaria, las perspectivas de crecimiento en cada uno de esos lugares están cada día más férreamente regidas por las condiciones que allí se ofrezcan para la valorización privada del capital;

- y, en tercer lugar, que en este tipo de sociedad, la factibilidad de promover objetivos sociales de interés general (y, en especial, de interés para los más desfavorecidos), está condicionada por la compatibilidad de esos objetivos con los de los propietarios del capital.

En base a las conclusiones derivadas de esta perspectiva teórico-ideológica, que resulta- ban avaladas por la evidencia brindada por la realidad, llegué a la conclusión de que los objetivos sociales del discurso desarrollista, tal como entonces habían sido expuestos, fundamentados y difundidos, carecían de viabilidad política y económica efectiva en una construcción social con los atributos antes señalados. Analizadas desde esta óptica, las ideas y propuestas sobre desarrollo y planificación de la CEPAL, así como también las de otros organismos internacionales y de algunos de los más influyentes economistas de esa época (Myrdal, Tinbergen, Rosenstein-Rodan, Nurkse, etc.), se podía llegar a la conclusión de que ellas estaban concebidas en base a supuestos y elementos principalmente de teoría económica, que prestaban escasa importancia a las restricciones que se derivaban de la existencia de una institucionalidad y una lógica capitalista y de una específica matriz de poder social, donde las decisiones de los propietarios del capital jugaban un papel central.

A medida que me fui afirmando en estas convicciones, me atreví a elaborar y publicar algunos trabajos en los que en forma todavía bastante tímida, comencé a cuestionar los posibles alcances de una planificación normativa desarrollista. Así, en un artículo publicado en 1979 en la Revista de la CEPAL sobre planes y planificación me propuse cuestionar la utilización abusiva que se estaba haciendo del concepto y de la palabra "planificación” en estos países. Ante todo, porque me resultaba evidente que en ese momento lo que se estaba haciendo en nombre de la planificación no era mucho más que elaborar detallados y voluminosos planes de desarrollo, los cuales prácticamente no tenían relación alguna con las decisiones que los gobiernos respectivos adoptaban y ejecutaban en la práctica concreta. Como es obvio, una cosa es redactar planes-libro y otra, muy distinta, ejecutar de manera efectiva políticas públicas planificadas. Además, en este trabajo también intenté aportar argumentos para refutar la presunción de que era posible la existencia real del "planificador como agente de cambio social", personaje que en 
esa época era objeto de una idealización que no se correspondía con el papel que el mismo podía desempeñar en cualquier proceso político observable.

En lo fundamental, en este artículo intenté dar cuenta de que lo que se denominaba "planificación” era entonces apenas una intención sin convalidación efectiva en la realidad; sin embargo, debo reconocer que en este artículo no me atreví todavía a plantear un cuestionamiento general de la posibilidad de materializar procesos concretos de desarrollo económico y social en una sociedad capitalista.

Por otra parte, en otra de mis vertientes de trabajo, desde mi adscripción al ILPES dediqué un esfuerzo especial a analizar y explicar los orígenes de las principales tendencias que se podían identificar en la evolución de la estructuración geográfica de estos países, bajo el avance de los procesos de integración económico-territorial capitalista motorizados por la industrialización sustitutiva. En esa dirección, en el primer artículo que publiqué luego de mi llegada a Chile en 1972, que dediqué al análisis de la movilidad espacial de recursos bajo una dinámica centro-periferia, traté de identificar las razones por las cuales desde las primeras etapas de la industrialización las disparidades regionales mostraban una clara tendencia a agudizarse, en forma independiente de cuál fuese la tasa de crecimiento de cada país y cómo, al mismo tiempo, en una situación de libre mercado se imponía una dinámica en la que los recursos financieros y humanos tendían a orientarse preferentemente hacia las áreas centrales, en un proceso de corte cepalino/myrdaliano de retroalimentación circular acumulativa.

En los años siguientes publiqué varios artículos en la misma dirección, con mayor énfasis en el análisis de los procesos de concentración geográfica productiva y demográfica. De ese conjunto de trabajos, quiero hacer una breve referencia a uno de ellos, por cuanto considero que en él logré presentar los lineamientos básicos de un enfoque sobre el que continué trabajando desde entonces. Se trata de un artículo publicado en 1982, también en la Revista de la Cepal, sobre "los límites de lo posible en la planificación regional”, en el que me propuse vincular los procesos de integración territorial capitalista, la evolución de los problemas regionales y urbanos y las posibilidades de la planificación regional.

Con este propósito, la argumentación de este artículo partía del hecho de que con el avance de la industrialización sustitutiva, se intensificaba la difusión y adopción de relaciones mercantiles y salariales a lo largo y a lo ancho de cada territorio nacional, lo cual ocasionaba dos efectos fundamentales: por un lado, aumentaba la articulación económica y social entre distintas partes de cada sistema nacional y, por otro, con ello, imponía una racionalidad capitalista dominante a la dinámica económica del sistema emergente en su conjunto. Lo cual, a su vez, por encima de la prioridad discursiva de atenuar las disparidades regionales, produjo en la realidad observable de los países afectados un sostenido aumento de las migraciones campo-ciudad y, consecuentemente, de la urbanización, así como una mayor concentración territorial de las actividades productivas y de la población en un número limitado de grandes aglomeraciones urbanas.

Con la evidencia de que estas tendencias realmente ya estaban presentes en los países más importantes de la región, lo que busqué fue aportar elementos de juicio a favor de la tesis de este trabajo, en cuanto a que "[...] la racionalidad dominante en el sistema, por una parte, y el contenido del proyecto político vigente, por otra, establecen los límites de lo posible para la acción social en cada situación concreta y, en consecuencia, para los trabajos y propuestas de los planificadores que efectivamente actúan como tales" (90).

Éste y otros trabajos elaborados en este período, me permitieron ir identificando las principales tendencias que se podían observar en los procesos de configuración geográfica industrial-desarrollista en estos países, entre las que estimo importante destacar las siguientes: 
- Primero: con el avance de los procesos de integración económico territorial se produjo un significativo aumento de la movilidad interregional del capital, de las mercancías y de la población, conforme a una dinámica centro-periferia, de la que resultaron favorecidas las regiones centrales y desfavorecidas las regiones periféricas;

- Segundo: en lo medular, esta dinámica condujo, en forma generalizada, al fortalecimiento de un número reducido de grandes centros territoriales de acumulación y crecimiento en cada espacio nacional, consolidando una situación marcada por acentuadas desigualdades interregionales y, en la mayor parte de los casos, por una tendencia a la metropolización, y aun, en algunos casos, a la macrocefalia urbana;

- Tercero: los intentos por implementar planes y políticas de desarrollo regional orientadas a mejorar la situación de las regiones menos desarrolladas, por lo general, tuvieron un carácter marginal e inoperante frente a la dinámica centroperiferia, en la que también a escala subnacional incidió el deterioro de los términos de intercambio.

Gobernanza y crecimiento en una nueva fase de modernización capitalista

Pero, el clivaje que se produjo desde fines de la década de los años setenta iba a alterar sustantivamente estas tendencias. Para entonces, ya era por demás evidente el irreversible agotamiento del modelo industrial-desarrollista, cuyos síntomas se traducían en un creciente deterioro del ambiente social y político en los principales países de esta parte del mundo. Fue así que en buena parte de ellos se multiplicaron las manifestaciones de descontento, incluyendo en varios casos la irrupción de movimientos insurgentes y, aun, la búsqueda de salida por la vía de las dictaduras militares.

Desde entonces, la respuesta generalizada fue, paulatina y progresivamente, un radical cambio de rumbo en la orientación y en la modalidad de la gestión pública, la que pasó a sustentarse en un discurso teórico-ideológico de corte neoliberal, que postuló el retorno a una dinámica económica genuinamente capitalista, sustentada en el libre juego de las fuerzas del mercado, lo cual implicó la puesta en marcha de procesos de reestructuración (o de "ajuste" estructural), motivados por el objetivo central de maximizar el crecimiento económico. Esto, en el entendido de que con el cumplimiento de este objetivo se podrían superar naturalmente los problemas sociales que habían constituido una de las prioridades discursivas del relato del desarrollo económico y social. Y, como camino para impulsar ese crecimiento, se preconizó la sustitución del fuerte intervencionismo estatal que comportaba la planificación desarrollista, por una modalidad de acción social basada en los principios de subsidiariedad y neutralidad del Estado, bajo el supuesto de que la acción concertada de los actores sociales involucrados conformaba el medio adecuado para la superación de los problemas que motivaban ese tipo de gestión.

En lo medular, esta transición desde el desarrollo al crecimiento y desde la planificación a la gobernanza empresarialista, implicó dos cambios sustantivos:

- primero, una significativa atenuación de la preocupación explícita por el problema de las desigualdades sociales, dado que ahora se asumía el supuesto de que éste sería un tema que tendría respuesta implícita con un sostenido crecimiento económico;

- segundo, una drástica reducción de la intervención directa del Estado en la vida económica, dado que la concepción que entonces se impuso consideraba que su neutralidad y subsidiariedad eran condiciones necesarias para llevar a la imposición de una gobernanza que permitiese intensificar la participación de los principales actores sociales involucrados en el proceso de crecimiento. 
En la medida que los cambios impulsados por la reestructuración neoliberal se propusieron despejar el terreno para un mejor despliegue de la lógica capitalista de acumulación y crecimiento -en un ámbito geográfico que desbordaba en forma continua sus fronteras- rápidamente se pudo comprobar que las tendencias que habían caracterizado a la geografía industrial-desarrollista se alteraban en forma substancial.

Tanto la globalización financiera como la productiva y de consumo, que habían impuesto, por una parte, la autonomía prácticamente total de los flujos con respecto a los lugares y, por otra, la creciente desverticalización y deslocalización hacia múltiples rincones del planeta de los componentes de un número cada día mayor de empresas transnacionales organizadas en red, incidieron en la afirmación de lo que puede considerarse como la nueva geografía de la globalización. En este nuevo escenario, las grandes áreas urbanas pasaron a constituirse en los ejes articuladores del capitalismo global, y al hacerlo se inició en ellas una metamorfosis de la que ha ido emergiendo una nueva forma urbana.

El conjunto de mutaciones que esto había comenzado a producir, impuso la necesidad de analizar su especificidad y alcance para el ámbito latinoamericano, donde los primeros estudios con este propósito hicieron su aparición en la década de los años ochenta, en especial en aquellos países donde estos cambios tenían mayor presencia. En particular, creo que diversos trabajos presentados en un seminario que me correspondió organizar en Santiago en 1989 -durante mi último año de permanencia en el ILPES- sobre "Revolución tecnológica y reestructuración productiva: impactos y desafíos territoriales", permitieron apreciar hasta qué punto los impactos geográficos de esta nueva fase de urbanización capitalista ya estaban presentes en esta parte del mundo.

¿Hacia dónde se orientaron mis preocupaciones frente a estos cambios? $\mathrm{Al}$ retornar al ámbito universitario ante todo decidí reenfocar mis trabajos hacia los temas relacionados con los impactos geográficos y urbanos de la globalización, con especial referencia al caso chileno. En los hechos, esta nueva ubicación laboral me permitió disponer de más tiempo y, sobre todo, de un ambiente más estimulante para la investigación teórica y empírica, la cual, en lo medular, se orientó hacia la identificación y explicación del impacto geográfico de esta nueva fase de modernización capitalista, con especial énfasis en la caracterización de las principales tendencias y rasgos de la metamorfosis que están viviendo las grandes áreas urbanas de esta región. Al mismo tiempo, me fue posible incorporar nuevos temas de investigación, como el de la competitividad interurbana al que ahora estoy dedicado junto a un equipo del Instituto de Estudios Urbanos.

¿Con qué antecedentes pude contar para estos estudios? En lo fundamental, con los aportados por un amplio número de investigaciones recientes, entre las que tuvieron particular importancia las presentadas en las reuniones del grupo de trabajo sobre cuestiones metropolitanas de la Red Iberoamericana de Investigadores sobre Globalización y Territorio; muchos de ellas contenían elementos de juicio novedosos, que permitieron plantear nuevas hipótesis y conclusiones sobre las transformaciones urbanas y territoriales de los últimos años en esta región. Con estos antecedentes, fue posible identificar algunos importantes cambios que habían comenzado a procesarse al profundizarse la reestructuración. Al respecto, puedo mencionar algunas investigaciones realizadas en esta fase y reseñar alguna de sus conclusiones:

Como un primer paso de esta nueva fase, realicé un estudio sobre los efectos territoriales de la tendencia a la centralización y concentración del capital que, de acuerdo a las conclusiones de diversos estudios realizados para Argentina, Chile y Uruguay, se estaba fortaleciendo con el avance de la liberalización económica. En este sentido, se podía comprobar que el eje central de 
la dinámica de acumulación en estos países tendía a vertebrarse principalmente en torno a las decisiones de inversión de las grandes empresas y de los principales grupos económicos, en procesos en los que se estaba imponiendo una progresiva pérdida de las raíces territoriales del capital. La afirmación de esta tendencia a la desterritorialización del capital aportaba importantes elementos de juicio para cuestionar los fundamentos teóricos de la alegada efectividad de las propuestas de acción territorial desde abajo hacia arriba, que constituyen la base de muchas estrategias de desarrollo local.

Por otra parte, al instalarme en el Instituto de Estudios Urbanos de la PUC, pude involucrarme en varias investigaciones empíricas, de las cuales me importa destacar dos de las que me correspondió coordinar, por cuanto creo que llegaron a algunas conclusiones importantes sobre ciertas mutaciones territoriales y urbanas que estaban comenzando a producirse en Chile bajo los efectos de la reestructuración: la primera, sobre las tendencias locacionales de la industria postliberalización y, la segunda, sobre los cambios en la configuración socioterritorial en Santiago de Chile en el período intercensal 1992-2002.

En forma extremadamente esquemática puedo destacar que las conclusiones de estas investigaciones mostraron dos tendencias importantes:

- la primera permitió comprobar que una vez recuperado el dinamismo económico en Chile, la industria volvió a mostrar su preferencia por localizaciones en la región central, donde el peso de las economías de aglomeración del Área Metropolitana de Santiago es determinante.

- por su parte, la segunda investigación mostró que la información sobre la evolución de la distribución de los distintos grupos socioprofesionales en el AMS no confirmaba aquí la llamada "hipótesis de la ciudad global" sobre intensificación de la polarización social, puesto que la información disponible indicaba un mayor crecimiento relativo de los sectores medios, aun cuando estos sectores son cualitativamente distintos de la clase media de la época industrial-desarrollista.

En cualquier caso, en forma relacionada con estos temas, la cuestión a la que he dedicado más tiempo durante estos años ha sido la relativa a las transformaciones urbanas y metropolitanas bajo el impacto de la globalización. En esta dirección, ante todo, he estado tratando de esbozar un cuadro general sobre la metamorfosis que afecta a las principales aglomeraciones urbanas latinoamericanas, donde la evidencia suministrada por un gran número de investigaciones realizadas para diferentes urbes de esta parte del mundo, indica que se ha desencadenado una tendencia generalizada hacia una metropolización expandida y descontrolada, que está produciendo configuraciones urbanas de fronteras difusas y extensión regional, con una organización policéntrica y fragmentada. Todo ello confirma la tesis planteada ya en 1970 por Lefebvre sobre una tendencia a lo urbano generalizado resultante de una revolución urbana que afectaría al planeta en su conjunto.

Durante los años más recientes, también comencé a trabajar sobre el incontenible crecimiento de la inversión inmobiliaria, con financiamiento nacional y/o extranjero, en las grandes áreas urbanas latinoamericanas. Con estos trabajos me propuse mostrar cómo se han originado procesos de creciente mercantilización del desarrollo urbano, en los que la plusvalía urbana se ha transformado en un criterio urbanístico dominante, con lo cual los negocios inmobiliarios han pasado a tener una influencia relevante en la organización, el funcionamiento, la morfología y la apariencia urbanas, contribuyendo en particular a intensificar la expansión descontrolada de estas aglomeraciones.

Complementariamente, como aproximación a un caso concreto de este tipo de metamorfosis, he tratado de analizar los cam- 
bios en la organización, el funcionamiento, la morfología y la apariencia urbanas en el AMS, tema sobre el cual he publicado varios artículos desde 1996 y, al mismo tiempo, he presentado varias ponencias en distintos seminarios y talleres sobre transformación urbana en América Latina y en Chile.

Situación emergente: frente a una crisis social y ambiental de difícil reversión

¿A dónde hemos llegado en el curso de esta evolución? Quizás la principal conclusión a destacar es que la agudización de los problemas sociales y ambientales, resultantes de los cambios a los que hemos sometido a nuestro planeta, parecen estar conduciéndonos a un punto crítico, desde el que el retorno a una situación de mayor equilibrio parece cada día más difícil.

En este sentido, no parece haber elementos de juicio que permitan contradecir la afirmación de que -no obstante todos los augurios y supuestos respecto a los beneficiosos efectos sociales que acarrearía la liberalización económica- durante las últimas décadas las desigualdades sociales han seguido aumentando y los niveles de pobreza y de exclusión social continúan siendo insoportables en buena parte del orbe. Y esto concierne, como nunca antes, a nuestros mundos urbanos. $\mathrm{Al}$ respecto, la información disponible, incluso la de origen gubernamental, avala ampliamente la conclusión consignada en el informe de Hábitat sobre los desafíos de los tugurios:

en lugar de ser un foco de crecimiento y prosperidad, las ciudades se han transformado en una tierra inundada por un excedente de población trabajando en servicios industriales y comerciales no calificados, desprotegidos y de bajos salarios (Hábitat, 2003).

Por otra parte, el calentamiento global no es más que uno de los más preocupantes síntomas del deterioro ambiental que hasta ahora ha continuado agudizándose en forma incontrolable, acompañado, entre otros, por una progresiva pérdida de biodiversidad, donde uno de los fenómenos que tiene mayor incidencia en que esta situación tienda a agravarse aún más, es la descontrolada expansión territorial de las grandes áreas urbanas, en la que juega un papel central el continuo y creciente uso del automóvil y el consecuente consumo, también descontrolado, de combustibles fósiles no renovables.

Sin embargo, sin mayor dificultad podemos comprobar que existe abundante evidencia de que estos temas y estos problemas no son verdaderamente prioritarios para la mayor parte de los gobiernos de los países más poderosos del mundo y que es muy fuerte la resistencia a modificar los factores que más inciden en la persistencia de este escenario. La resistencia a suscribir el Protocolo de Kioto, así como el reciente fracaso de la cumbre ambiental de Copenhague, constituyen un testimonio irrebatible de ello. Además, cada día podemos encontrar diversos testimonios acerca de que los decisores económicos, en especial los dirigentes y los accionistas de las empresas cuyas actividades aparecen más relacionadas con la generación de los más graves problemas sociales y ambientales, muestran una postura hostil a cualquier propuesta de modificación del statu quo.

¿Significa todo esto que estamos ante un callejón sin salida? Plantear todo esto, ¿̇ignifica asumir una posición catastrofista o apocalíptica? La respuesta, en mi opinión, debería ser negativa, por cuanto creo que lo que no tiene justificación alguna es intentar silenciar la preocupación que produce esta evolución, sobre cuya existencia día a día acumulamos evidencia adicional. Creo firmemente que si en realidad queremos evitar el advenimiento de una catástrofe, es imperioso analizar y denunciar, en forma explícita y directa, todos aquellos hechos y tendencias que contribuyen a llevarnos hacia una situación que podría no tener retorno.

Estoy plenamente convencido que ciertas posturas, bastante frecuentes por cierto, que tienden a descalificar o a minimizar las preocupaciones por el agravamiento de estas tendencias, ya sea negando su intensificación 
o, aun, su existencia, o bien asumiendo que la propia evolución tecnológica habrá de proveer respuestas antes de llegar a la catástrofe, son esencialmente autodestructivas.

¿Qué hacer entonces frente a esta situación? Es obvio que no tengo una respuesta satisfactoria a esta pregunta, más allá de reafirmar la necesidad ineludible de asumir una postura crítica y combativa frente a la evolución que estamos viviendo. Por lo tanto, al mismo tiempo que en esta oportunidad no puedo dejar de plantear esta inquietud, quiero dejar abierta esta presentación, afirmando algo también obvio: que la respuesta y la salida a esta grave encrucijada está en cada uno y en todos nosotros. Donde cada uno debe actuar según sus convicciones y sus posibilidades, en la búsqueda de caminos que nos permitan salir de este atolladero. IEURE

\section{Referencias bibliográficas}

Habermas, J. (1975). Problemas de legitimación en el capitalismo tardio. Buenos Aires: Amorrortu Editores.

Lefebvre, H. (1970). La revolution urbaine. Paris: Gallimard.

UN-Hábitat (2003). The Challenge of Slums. Global Report on Human Settlements 2003. Londres: Earthscan Publication.

\section{Algunas referencias personales}

(1972). Algunas consideraciones sobre movilidad espacial de recursos en los países latinoamericanos. EURE, n. 6., noviembre, Santiago de Chile.

(1979). Planes versus planificación en la experiencia latinoamericana. Revista de la CEPAL, n. 8, agosto, Santiago de Chile.

(1982). Los límites de lo posible en planificación regional. Revista de la CEPAL, n. 18, diciembre, Santiago de Chile.

(1984) A dinámica concentradora e centralizadora nos procesos de formação das estructuras territoriais. Revista Económica do Nordeste, v. 15, n. 2, abril-junio, Fortaleza, Brasil.
(1989). Reestructuración social, grupos económicos y desterritorialización del capital. El caso de los países del Cono Sur. EURE, n. 47, diciembre, Santiago de Chile.

(1990). La descentralización, ¿una nueva panacea para impulsar el desarrollo local? ESEconomía y Sociedad (Revista de Estudios Regionales de la Comunidad de Madrid), n. 3, marzo, Madrid.

(1992). Nuevas estrategias empresariales y mutaciones territoriales en los procesos de reestructuración en América Latina. Revista Paraguaya de Sociología, n. 84. mayo-agosto, Asunción.

(1993). La obstinada marginalidad de las políticas territoriales: el caso latinoamericano. Revista de Estudios Regionales, n. 35, octubre, Málaga, España.

(1995). Reestructuración, globalización, nuevo poder económico y territorio en el Chile de los noventa. Revista de Estudios Regionales, n. 43, septiembre-diciembre, Málaga, España.

(1996). Avances de la globalización y nueva dinámica metropolitana: Santiago de Chile, 1975-1995. EURE, n. 65, junio, Santiago de Chile.

(1999). Santiago de Chile, globalización y expansión metropolitana: lo que existía sigue existiendo. EURE, n. 76, diciembre, Santiago de Chile.

(2002). Santiago de Chile de cara a la globalización, ¿otra ciudad? Revista de Sociología e Politica, n. 19, noviembre, Curitiba, Brasil. (2002). Mercado metropolitano de trabajo y desigualdades sociales en el Gran Santiago, ¿una ciudad dual? EURE, n. 85, diciembre, Santiago de Chile.

(2003). Redes, nodos y ciudades. Transformación de la metrópoli latinoamericana. Regiones y desarrollo sustentable, n. 5, juliodiciembre, Tlaxcala, México.

(2004). De la planificación a la governance. Implicancias para la gestión territorial y urbana. Revista Paranaense de Desenvolvimento, n. 107, julio-diciembre, Curitiba. (2007). Globalización, negocios inmobiliarios y transformación urbana. Nueva Sociedad, n. 212, noviembre-diciembre, Buenos Aires. 
(2008). Cambios socio-ocupacionales y transformación metropolitana del Gran Santiago, 1992-2002. En BBVA, Mercado y ciudad. Desafios de un país urbano. Santiago: Banco BBVA-Observatorio de Ciudades FADEU/PUC.

(2009). Modernización capitalista y revolución urbana en América Latina. En P. Brand (ed.), La ciudad latinoamericana en el siglo XXI. Globalización, neoliberalismo, planeación. Medellín: Universidad Nacional de Colombia.

(2010). Globalización y metamorfosis metropolitana en América Latina. De la ciudad a lo urbano generalizado. Grupo Estudios sobre Desarrollo Urbano, Documento de Trabajo, n. 8, Madrid. www.gedeur.es 